\title{
A tipificação do totalitarismo segundo Hannah Arendt
}

\author{
Odilio Alves Aguiar \\ Universidade Federal do Ceará - UFC \\ Odílio@uol.com.br
}

resumo Este ensaio expõe parte de uma pesquisa sobre a relação entre natureza e política, com ênfase nos processos de naturalização da vida humana na filosofia política contemporânea. 0 totalitarismo e o domínio total em Hannah Arendt é o aspecto da pesquisa sobre o qual iremos nos deter neste texto. Partiremos do totalitarismo como categoria narracional. Apresentaremos a novidade da forma totalitária de governar; sua base na passagem da questão judaica ao mal radical; as alterações, relacionadas ao tema do poder, serão expostas a partir dos elementos tipificadores do totalitarismo segundo Arendt: massificação, propaganda, movimento-organização, solidão e campos de concentração.

palavras-chave totalitarismo; naturalização; massificação; campos de concentração; ideologia; terror.

Partimos da compreensão de que totalitarismo em Arendt não é uma categoria científica ou ética, mas narracional. Em Origens do Totalitarismo (1951) e em outros textos publicados no momento da escritura dessa obra, Arendt fala do inferno, de pesadelo, da Metamorfose de Kafka, da cebola, da feitura da omelete, entre outras imagens, visando exprimir o seu assombro e compreender o que estava se passando na Alemanha a partir das notícias que chegavam às suas mãos em 1943 sobre Auschwitz. Trata-se de um conceito intimamente relacionado à experiência que marcou o seu pensamento no nascedouro da sua Filosofia Política e em toda sua obra posterior. A experiência totalitária a tornou uma contadora de histórias (storyteller). Vale dizer, ao tentar escrever sobre a experiên- 


\section{4}

cia totalitária, Arendt deparou-se com um dilema, já que essa experiência não podia ser explicada, pois não se enquadrava nos conceitos tradicionais, tampouco podia ser entendida como culminação de um processo ou desenvolvimento de uma única causa encontrável no passado. Não era o passado que poderia iluminar e explicar o evento. Não se tratava de uma evolução, de algo que podia ser deduzido de uma causa antecedente. A saída que Arendt encontrou foi narrar a experiência. Nessa prática, verificou que o próprio acontecimento ilumina o que no passado pode a ele estar relacionado. O totalitarismo não possui uma história e nem estava contido potencialmente num evento do passado, mas cristalizou elementos de várias proveniências, a exemplo do imperialismo, do antisemitismo, da crise dos estados nacionais e do eurocentrismo. A respeito, numa polêmica com Voegelin sobre o método do livro acima referido, diz: "eu não escrevi uma história do totalitarismo, mas uma análise em termos históricos dos elementos que se cristalizaram no totalitarismo". (ARENDT, 1994, p. 403).

Em Compreensão e Política (1954), artigo que publicou logo após o livro sobre o totalitarismo, Arendt depara-se com o "problema epistemológico" mencionado e aponta a narrativa como saída. A narrativa, em Origens do Totalitarismo, apresenta-se não como mera descrição dos fatos, mas como um modo de pensá-los. A autora quer entender o que, por que e como foram possíveis os campos de concentração (ARENDT, 1990, p. 339). Talvez isso tenha gerado várias incompreensões, pois exigiam do livro algo que a pensadora não pretendia dele: que fosse um livro de ciência histórica. Isaiah Berlin e Eric Voegelin, entre outros, reclamam do procedimento arendtiano. $\mathrm{O}$ primeiro queixa-se de várias inexatidões factuais e o segundo questiona o amplo uso de metáforas no livro (VOEGELIN, 1953; COCKS, 2002). Eles não entendiam que Arendt, na verdade, estava realizando um "exercício de pensamento".Visava, antes de tudo, incitar à compreensão, muitas vezes, através do recurso metafórico. Isto é, o importante não é a reprodução, o espelhamento descritivo do que ocorreu, mas a fidelidade total às experiências geradoras dos pensamentos em pauta e isso eles não podiam questionar na obra arendtiana. Eles não entenderam que Origens do Totalitarismo não é para ser lido como livro de ciência, mas de filosofia. Nele, a Autora está pensando e não apenas reconstituindo os fatos. Trata-se de um pensamento à procura, nos 
trágicos eventos da primeira metade do século XX, de algum sentido capaz de iluminá-los.

A perspectiva narrativa escolhida por Arendt põe-se entre o objetivismo redutor de tudo ao econômico e o subjetivismo explicador da história a partir da perspectiva moral, cultural e lingüística. São narrativas que tentam alcançar o paradoxo e o paroxismo da situação contemporânea: o alto desenvolvimento da capacidade humana de dominar e controlar a realidade e o perigo da aplicação dessa potência ao universo humano, tais como a crise da autoridade, o fim da política, a redução da palavra a signo, a devastação da natureza, a solidão, o medo, a violência, a purificação e o extermínio humano, entre outras tendências do nosso tempo.

A percepção do surgimento de uma nova modalidade de controle e dominação dos humanos, perpassada pela lógica da violência, guerra e morte, foi a grande intuição de Arendt em Origens. Essa é a razão dela ter ido muito além de uma visão judaica da experiência totalitária, embora sem a sua condição de judia dificilmente teria chegado aonde chegou para a compreensão do fenômeno. Os campos de concentração colocam em cena o genocídio, naquele momento, um tipo de crime sem nenhuma tipificação nos códigos do direito, na literatura ética ou na filosofia política. Trata-se, pela primeira vez na história do Ocidente, da instauração de uma forma de governo erguida em contraposição ao próprio gênero humano.

O governo totalitário ultrapassa, assim, o preconceito, a perseguição a um agrupamento humano específico ou a expropriação territorial. Não se tratava mais, evidentemente, de um preconceito social ou religioso, mas de um Estado que alterava a essência mesma da política e foi justamente isso que os judeus não entenderam. Presos à mentalidade da nação escolhida e da perseguição religiosa, os judeus não perceberam que estavam diante de algo muito diferente e não apenas de proporções maiores. Holocausto, sacrifício não dá conta da novidade desse acontecimento. Uma nova forma de governo, com ambição de dominação total, estava surgindo estribada na idéia de purificação, extinção de raças e outros setores da população. O temor de Arendt, muito bem percebido por Giorgio Agamben (2002), é que essa nova instituição pairasse como um espectro exemplar e se constituísse como parte essencial da vida contem- 
porânea. Arendt é enfática em Origens do Totalitarismo: estamos diante de uma nova forma de governo (CHAUMONT, 1992). Por essa razão, sua reflexão ultrapassou a circunscrição da questão judaica e passou a dizer respeito a todos nós. A caracterização do totalitarismo que iremos descritivamente apresentar à frente é uma maneira de chamar atenção para a similitude entre as nossas condições e formas sociais predominantes e as aquelas que nasceram com a experiência totalitária apresentada por Arendt em Origens do Totalitarismo.

Para Arendt, os eventos totalitários apontam retroativamente para três grandes eixos possibilitadores da compreensão dos fenômenos totalitários: o anti-semitismo, o imperialismo e o domínio total. O totalitarismo converteu o anti-semitismo de preconceito social, comum na história européia, em discriminação política legal. Esse preconceito era alimentado pela idéia de que os judeus eram ricos, manipulavam o Estado e estavam organizados internacionalmente. O imperialismo, guiado pela conquista global dos territórios e expansão dos mercados, levou a Europa para outros continentes, provocou a decadência do Estado Nacional e assumiu o racismo como justificativa biológica para dominação dos povos na África, América, Ásia e Oceania. Iremos nos dedicar à última parte, a dominação total, pois aí se encontram os aspectos que mais podem interessar à Filosofia Política, isto é, a uma reflexão interessada em captar a novidade produzida pelo totalitarismo em relação ao tema do poder.

Exploraremos, assim, os elementos constitutivos da noção de totalitarismo em Arendt. Com isso, visamos seguir o conselho da Autora sobre o uso cauteloso do termo (ARENDT, 1990, p. 343). A idéia é mostrar as características, o conteúdo dos elementos que, segundo Arendt, tipificam o domínio total: massificação, propaganda, organização e movimento, solidão e campo de concentração. Esses aspectos são apresentados por Arendt na Terceira parte de Origens do Totalitarismo. Vale lembrar, para melhor compreensão desse assunto, que esses aspectos desenvolvem-se na seqüência do último item da Segunda Parte onde a Autora aborda o Imperialismo e expõe a crise dos direitos humanos. Nesse item, Arendt disserta sobre a insuficiência dos direitos humanos, pois a vida, defendida na declaração dos direitos humanos, conjugada com a idéia de nação, é abstrata, natural, biológica. A defesa abstrata da vida foi incapaz de barrar o mal radical, a descartabilidade dos homens como seres capazes de 
pensar e agir. Esse processo inicia-se com a desnacionalização, gera um contingente enorme de refugiados e se transforma no leitmotiv do domínio total e do extermínio.

Comecemos pelo tema da massificação. Segundo Arendt, os movimentos totalitários basearam seu poder no apoio das massas e das sociedades massificadas. Qual a compreensão da autora sobre as massas? Arendt, nesse aspecto, alia-se à maioria dos filósofos políticos contemporâneos na percepção das massas como pedra de toque da política. A base do poder não é constituída por sujeitos de direitos e deveres, capazes de contratar, representar, julgar, deliberar etc. Para ela, as massas são o resultado da decadência burguesa e suas instituições profundamente marcadas, no caso alemão, pela humilhação proveniente da derrota na Primeira Guerra Mundial e objetivada no Tratado de Versalhes (multas, indenizações, anexação da Lorena e Alsácia etc). Os movimentos totalitários constroem seu poder nas massas, na sua força, e não nas classes, partidos ou nos cidadãos. O colapso do sistema de classes, estruturador dos Estados Nacionais europeus após Primeira Guerra, está na base da percepção de Arendt a respeito da enorme importância que as massas passaram a desempenhar nos movimentos totalitários que as reivindicavam como inspiradoras. A inflação, o desemprego, os refugiados e apátridas, contingentes enormes de pessoas sem raiz e lugar na Europa, corroeram o tecido social e fizeram surgir novas categorias: as massas, o lumpen (a ralé), a elite, o filisteu, exemplos das categorias sustentadoras dos movimentos totalitários.

Essa situação de massificação social vai gerar o que Arendt chamou de psicologia do homem de massa, facilitando enormemente o seu aparelhamento pelos movimentos totalitários. A marca dessa psicologia é o desprezo aos padrões morais e à vida pública. Seu conteúdo é preenchido pelo racismo e anti-semitismo, pela busca do sucesso e da fama, na atribuição de grande valor ao gênio e a tudo que é abstratamente considerado superior, grandioso. Esse é o esteio para o "culto da personalidade" tão comum a todos os regimes totalitários. Os grandes líderes das massas entificavam esses valores e nutriam ódio às instituições burguesas por não lhes darem lugar nem os reconhecerem socialmente. Eles compartilham a mesma psicologia do homem de massa que, sem nenhum interesse e pertença ao mundo comum, vive isolado e solitário e é porta- 
dor de uma consciência de desimportância e dispensabilidade (selflessness). "A principal característica do homem de massa, escreve Arendt, não é a brutalidade nem a rudeza, mas seu isolamento e sua falta de relações sociais normais" (ARENDT, 1990, p. 367). As massas encontram-se fora de qualquer ramificação e representação política (ARENDT, 1990, p. 364).

Outra característica da mentalidade do homem de massa, capturada pelos movimentos totalitários, é o fato de le ser atraído pelas explicações científicas. A coerência, o necessitarismo cientificista, elide a contingência, naturaliza a realidade humana, apresentando-a como guiada pelas "forças das coisas". Diante dessa situação, nada pode ser feito a não ser colocar-se na direção do fluxo natural. $\mathrm{O}$ veredicto científico funciona como sucedâneo do poder (ARENDT, 1990, p. 394). A raça superior entifica essa força e fluxo natural. Trata-se de um elemento abstrato diminuidor do caráter supérfluo das massas e doador de sentido à sua existência, colocando-as ao lado dos mais fortes, melhores e puros, além de justificar o assassinato daqueles que não se situam ao lado dos vitoriosos. Ligar-se a esse fluxo é atrelar-se à "boa sorte" na corrente da fatalidade natural ou histórica (ARENDT, 1990, p. 395). Pelo exposto, o governo totalitário nutre-se das massas, tanto se apóia nelas como as devora vorazmente. Nesse regime, o poder não é uma qualidade do Estado ou da comunidade política, mas do movimento regido pela força natural da multidão, das massas.

Elemento importante dos movimentos totalitários reside na atração exercida sobre a elite intelectual, a intelligentsia (ARENDT, 1990, p. 366). Tem-se, assim, uma inversão da proximidade entre saber e bem, tão comum na visão tradicional do intelectual. Uma das características da elite era a grande sedução pela violência, pelo crime e pela guerra como condição para purgação da sociedade burguesa corrupta e dissimulada. Os intelectuais não suportavam a dupla moralidade burguesa (privada e pública) e ansiavam por uma vida autêntica, transparente e viam nas massas e na sua revolta a saída para essa situação. Isso possibilitou a aliança entre a elite intelectual e os movimentos de massa. Diz Arendt a respeito: "a atração da elite intelectual é um indício tão importante para compreensão dos movimentos totalitários quanto a sua ligação com a ralé” (ARENDT, 1990, p. 376). A crueldade é a saída à hipocrisia liberal que avaliava as instituições públicas pela medida dos seus interesses priva- 
dos. O mergulho nas forças sobre-humanas da destruição pode significar a única forma de escapar às funções pré-estabelecidas por uma sociedade cujo valor predominante é a competição, a falsa cultura, a falsa moralidade e o lucro (ARENDT, 1990, p. 381).

Arendt aponta a figura do filisteu como representativo do colapso das classes e da hegemonia das massas na política. Trata-se do burguês de espírito vulgar e estreito, sem a solidariedade de classe e sem o mundo burguês como pano de fundo. $O$ filisteu vive em função da carreira, do lucro e da família. Por esses valores ele é capaz de sacrificar qualquer crença, honra e dignidade. É guiado pelo espírito burguês que vê em tudo motivo para ganhar e lucrar, mas que faz isso isolado da própria classe e de um sistema social comum. O filisteismo é uma categoria que ajuda a compreender o suporte aos movimentos e regimes totalitários por parte de membros da classe burguesa.

A mudança introduzida na comunicação política pelos regimes totalitários é outra característica dos governos totalitários. Arendt percebe a novidade e a centralidade da propaganda como forma de comunicação política, isso está muito bem exposto no item "A propaganda totalitária" do capítulo O movimento totalitário da terceira parte de Origens do Totalitarismo. Segundo esse texto, os movimentos totalitários não criaram algo original, apenas importaram dos Estados Unidos as técnicas publicitárias utilizadas para vender mercadorias. Sobre isso, diz ela: "os nazistas aprenderam tanto com as organizações dos gângsteres americanos quanto a sua propaganda aprendeu com a publicidade comercial americana" (ARENDT, 1990, p. 394). Tal aprendizado tornou-se um pressuposto na comunicação publicitária estabelecida com a sociedade. A publicidade lida com os homens como meros seres vivos, isto é, ela segue o princípio da manipulabilidade dos homens colocado em voga pela psicologia behaviorista na primeira metade do século XX. A publicidade não enseja formar uma opinião, mas provocar um comportamento, gerar uma atuação. Esse é o ponto axial para Arendt em Origens do Totalitarismo. Subjaz à propaganda tanto política quanto comercial a idéia de que as massas podem ser conquistadas, dominadas e conduzidas e, por isso, toda e qualquer propaganda tem um traço de coerção. Nesse sentido, Arendt diz: "não apenas a propaganda política, mas toda a moderna publicidade de massa contém um elemento de coerção” (ARENDT, 1990, p. 390). 
Propaganda e violência não são contraditórias. O objetivo da propaganda não é a persuasão, mas o rigor da organização (ARENDT, 1990, p. 411). O uso da violência pode ser parte da propaganda. A propaganda está para a força da mesma forma que o poder está para a política. A propaganda e suas ficções são alimentadas pelo segredo, o mistério e o invisível. A coerção aqui abordada não é necessariamente física, mas seguindo o principio da manipulabilidade dos homens, utiliza-se de qualquer instância capaz de induzir o comportamento, como, por exemplo, os argumentos religiosos, científicos, os preconceitos e, muito freqüentemente, a mentira.

Segundo Arendt, o sucesso da propaganda nos regimes totalitários e nas sociedades de massas contemporâneas reside no controle do real que ela promete e na idéia de onipotência humana a ela subjacente. Seduz as massas, a possibilidade de "eliminação da incômoda imprevisibilidade das ações e da conduta do indivíduo" (ARENDT, 1990, p. 395). A promessa do controle é a razão pela qual a coerência da ficção atrai profundamente. A ficção garante não só a certeza, mas, também, a vitória. As massas desejam o sucesso. Para elas, diz Arendt, o importante não é a causa vitoriosa, mas a vitória em si mesma (ARENDT, 1990, p. 400). Daí o motivo da infalibilidade ser a principal qualidade do líder totalitário. Para manter essa infalibilidade, várias correções foram feitas na realidade durante a vigência dos regimes nazista e estalinista. Essa onipotência sobre os fatos atraia profundamente as massas no totalitarismo. "O que convence as massas não são os fatos, mas a coerência com o sistema do qual esses fatos fazem parte" (ARENDT, 1990, p. 401). Os fatos são sempre tomados como exemplos de leis gerais. "As massas recusam compreender a fortuidade de que a realidade é feita" (ARENDT, 1990, p. 401). Esse mundo coerente, a ficção, é importante porque dá uma explicação convincente para sua superfluidade. Gera-se, assim, um mundo através do qual "as massas desarraigadas podem sentir-se à vontade e evitar os eternos golpes que a vida e as experiências verdadeiras infligem aos seres humanos e às suas expectativas" (ARENDT, 1990, p. 402). Assim, a voz fraca do argumento cede lugar à força da organização e o poder, atributo da visibilidade, é assaltado pela invisibilidade e substituído pelas organizações secretas.

A organização totalitária se estabelece a partir do princípio da liderança e segue o sempre dinâmico e em movimento desejo do líder 
(Führer), lei suprema num Estado Totalitário. Arendt apresenta a metáfora da cebola para explicar o funcionamento das organizações totalitárias. A organização não é monolítica, mas construída em torno de funções superpostas (ARENDT, 1990, p. 346). Segundo esse modelo, um organismo do movimento funciona como casca, fachada para comunicar e proteger a hierarquia interna do movimento do mundo externo (ARENDT, 1990, p. 424). Isso exige do militante a identificação completa com o movimento, não tendo, por isso, profissão nem vida pessoal independente.

A ligação entre organização e movimento exige o estabelecimento de uma hierarquia flutuante ao estilo das polícias secretas. A polícia secreta se torna o núcleo do poder. O domínio da organização e do Estado pelo movimento totalitário provocou o surgimento da técnica da duplicação dos órgãos. Isso em função da necessidade de novos controladores para controlar os outros controladores. Para cada órgão era criado outro a fim de manter atuante dentro do governo e da sociedade a ideologia totalitária. É por isso que surgem a SS e a SA, duplicam-se os sindicatos, as associações estudantis etc. A organização propiciava aos seus membros a separação total dos vínculos normais (leis, famílias, partidos, interesses etc) e era o sucedâneo a essas raízes do mundo comum. Esse formato da organização exigia uma profunda identificação entre o líder e os militantes. Era como se tivessem um corpo único, indiferenciado, dotados de uma só vontade em ação. A disciplina é férrea e a lealdade é absoluta. A feição secreta produz a atuação externa do movimento como jogo de trapaça. O tático toma lugar do estratégico, a mentira o lugar da informação. A organização, a força do movimento, vai gerar nos seus membros a crença na onipotência humana. A prática totalitária é moralmente cínica, repousa na crença de que tudo é permitido e na convicção de que tudo é possível. Arendt associa diretamente a pretensão de dominação global à crença totalitária na onipotência humana, ao desdém para tudo que é limitador: os fatos, as leis, os limites geográficos, a doença e a morte. A luta é pelo domínio total da população da terra.

Todos esses aspectos confluem para o emblema máximo e fundamento do totalitarismo: os campos de concentração. A supremacia da polícia secreta, o papel das massas, a propaganda como forma de comunicação, a organização e o movimento como os detentores do poder efetivo e pro- 
pugnadores das leis supra-constitucionais vão ser reunidos e sistematizados numa forma nova de governo baseada nos campos de concentração e extermínio. O Estado será um instrumento e os campos de concentração o laboratório de teste desse domínio total (ARENDT, 1990, p. 442). Erra, assim, quem reduz os campos de concentração a campos de execução, é mais do que isso. É o núcleo e o modelo de uma nova forma de governo e sociedade cujo telos é a fabricação do animal humano, funcional, limpo, puro, saudável.

Altera-se, dessa forma, o conceito tradicional de lei e sua relação com o poder político. A lei é proveniente diretamente da própria natureza encarnada na vontade do Líder, não resulta de um consensus júris ou de um contrato. Da mesma forma, Partido, sindicato, Estado não se diferenciam, mas se superpõe conduzidos pela lógica do movimento. As coisas são desse modo para que não haja qualquer estorvo à expansão da organização. $\mathrm{O}$ certo é que quanto mais visível é uma agência governamental, menos poder detém e quanto menos se sabe da existência de uma instituição, mais poderosa ela é. O poder começa onde o segredo se estabelece. Atrás dos regimes totalitários temos um conceito completamente novo de poder, concebido, desta feita, como a "força produzida pela organização" e, enquanto tal, liga-se à ficção ideológica e não ao povo, ao Estado, à lei. O poder está a serviço da aceleração implacável da seleção natural ou histórica (ARENDT, 1990, p. 441) e, para tanto, é investido nas instituições do movimento, fora da estrutura do Partido, do Estado e do Exército. Esses são apenas fachadas para o mundo não-totalitário. O primado absoluto do movimento sobre quaisquer interesses locais, econômicos, nacionais, militares, gerou o caráter anti-utilitário do poder totalitário.

Essa postura anti-utilitária dos movimentos e regimes totalitários manifesta-se na formação dos governos totalitários. No primeiro estágio, procuram-se os inimigos secretos e são caçados os antigos oponentes, arregimentando serviços voluntários de espionagem. Depois do extermínio dos reais inimigos, dá-se o início da caça aos inimigos objetivos, determinados ideologicamente. $\mathrm{O}$ terror se instala e com ele as fábricas de morte em massa. Os inimigos objetivos não são julgados pelas suas ações ou opiniões, mas pelo crivo ficcional proveniente da ideologia e podem ser encontrados, conforme as circunstâncias, no judeu, no polonês, nos ciganos, nos doentes etc. O inimigo objetivo é o "resto" dos 
humanos alimentadores da voracidade mortal do regime. O dever da polícia não é descobrir crimes, mas aprisionar ou liquidar essa categoria da população. O fim último é o controle total da população, a manipulação e padronização das reações humanas já em teste nos laboratórios de extermínio. Os campos produzem o animal humano adequado ao controle técnico e ideológico. A queda da liberdade não é proveniente apenas da arbitrariedade do líder ou do movimento, mas principalmente dos mecanismos de controle, expressão da onipotência da organização testada nos campos de concentração. A morte como lógica do poder se expõe, assim, de forma organizada.

Não existe totalitarismo sem campo de concentração. O campo é a certeza de que o objetivo final pode ser alcançado: a sistematização da infinita pluralidade de experiências e diferenciações dos seres humanos, a fabricação da espécie humana com a mesma identidade. Almeja-se a eliminação, em condições cientificamente controladas, da espontaneidade na conduta humana. O campo significa que os governos totalitários se alimentam do extermínio dos humanos indesejados, doentes, racialmente inferiores, naturalmente deformados e socialmente desempregados. Sempre vai existir um setor da população a ser sacrificada em nome do controle total, pois o processo de expansão da dominação não tem limite. O campo não é sinal de punição, banimento ou escravidão. Essas experiências se realizavam no contraponto do mundo comum, ou seja, de alguma forma, mantinham-se dentro do raio da visibilidade, da proteção dos seus semelhantes. No campo, as massas humanas são tratadas como se já não existissem, meros cadáveres-vivos.

O primeiro momento na transformação dos homens em cadáveres vivos é a morte da pessoa jurídica, excluí-la da proteção jurídica através do processo de desnacionalização. Elimina-se, desse modo, a capacidade de agir politicamente. Depois, o outro passo, é a morte da pessoa moral. Nesse momento, surgem dilemas como de Sofia, a mãe grega obrigada a escolher um dos três filhos para ser morto. A consciência moral deixa de ser adequada. O terceiro momento é o da morte da singularidade individual, visa-se matar as lembranças, a esperança, a forma pessoal de reagir ao mundo, aos eventos, às experiências. Acompanha essa situação a proibição da dor e da recordação. Ninguém chora a morte, nenhuma memória é possível, tudo é anônimo. Restam, agora, depois desses passos, 


\section{4}

apenas mortos vivos, homens e "cidadãos" adequados aos regimes totalitários. O governo totalitário baseia-se não no mundo comum, na troca das experiências imprevisíveis, alimentadora da espontaneidade humana, mas na tentativa de transformar o caráter dos homens, a sua natureza específica, tornando-o previsível, "animal" e supérfluo nas suas características específicas: agir e pensar. Arendt conclui alertando: "As soluções totalitárias podem muito bem sobreviver à queda dos regimes totalitários sob a forma de forte tentação que surgirá sempre que pareça impossível aliviar a miséria política, social ou econômica de um modo digno do homem" (ARENDT, 1990, p. 511).

Esse caráter central e emblemático dos campos de concentração na tipificação do totalitarismo também é exposto no texto "Ideologia e Terror" (1958). A questão posta inicialmente por Arendt é a respeito da novidade desse regime em relação à tirania, despotismo e ditadura, regimes arbitrários e violentos tradicionalmente classificados pela filosofia política. Trata-se, para ela, de saber se os governos totalitários constituíram uma nova forma de governo (STANLEY, 1994). Se estivermos de frente a um novo regime, significa que uma experiência completamente nova da humanidade passou a se constituir na essência do novo regime político. Essa experiência jamais foi tida como base dos regimes catalogados pela tradição. Para Arendt, a essência dessa nova forma de governo é o terror possibilitado pela solidão disseminada nas sociedades de massas contemporâneas, isto é, na experiência de não pertencer de modo algum ao mundo, de não estar protegido pela visibilidade humana própria ao mundo comum. Nessa situação, a fonte de autoridade não é o povo, o contrato, mas o movimento natural ou a força da história.

Nesse momento, percebemos a importância da ideologia. Os regimes tradicionais se organizavam a partir de princípios de ação (honra, virtude e medo), os governos totalitários organizam-se a partir de princípios do movimento: a ideologia. É a ideologia e sua disseminação que vão possibilitar a existência dos campos de mortes como algo normal e desejável. Arendt ressalta a importância da ideologia para caracterização dos regimes totalitários. $\mathrm{Na}$ compreensão dela, a ideologia não se reduz à falsa consciência, à percepção equivocada determinada pelos interesses hegemônicos. Mesmo nessa compreensão, há a liberdade de interação com a realidade. Para Arendt, o reino da ideologia é o reino da ficção, no 
qual o real é fabricado e não fruto das experiências vividas espontaneamente. A ideologia articula, em Arendt, a ficção e a fabricação da vida. Como doutrina, explica tudo; como propaganda, realiza-se na prática através das organizações. Por meio da ideologia é possível o cálculo e o controle do real a partir da ficção. Ideologia é sinônimo de doutrina, mas também de disciplina. O totalitarismo é o regime das massas solitárias organizadas ideologicamente.

Arendt atribui três características à ideologia: 1. A pretensão de explicação total; 2. a liberdade de toda experiência e o funcionamento na forma de propaganda; 3 . A coerência total produtora da coerção argumentativo-organizacional. A coerência e a coerção provêm da força da "objetividade" do argumento, da tirania da lógica. Por essa razão, diz Arendt, a violência é imanente à ideologia. Todas essas características são reunidas na experiência da solidão, jamais aceita como base de qualquer regime político. Em outras palavras, o totalitarismo inaugura, pela primeira vez na história do ocidente, uma forma de governo sem política. O desenraizamento, a desnacionalização e o fato de não pertencer ao mundo comum, a superfluidade das massas, tornam os homens meros animais laborans, cuja vida se resume à atividade de mero ser natural, visando apenas a reproduzir-se como ser vivo. $\mathrm{O}$ totalitarismo quer dos homens a vida biológica, nada mais. A identidade é apenas natural. Nesse estado de solidão, o animal laborans mostra-se incapaz de estabelecer uma relação humana para confirmar a própria identidade. Torna-se, desse modo, vulnerável e agarra-se a identificações fictícias como última possibilidade de sobrevivência da identidade. O outro já não é condição da constituição, realização e reconhecimento da identidade.

Por fim, vale dizer que a centralidade da ideologia nos governos totalitários provoca uma mudança enorme no estatuto da política, pois o poder deixa de ser pensado a partir da lógica do direito, da lei e da autoridade, isto é, do povo nos seus diversos modos de vida, culturas e costumes e passa a ser organizado em função da força bruta da multidão. O poder torna-se uma grandeza natural. A ideologia é a ponte que conduz a essa prática política ao exacerbar o preconceito, fixar a identidade e padronizar os comportamentos (Cf. 1998, especialmente a parte 2, p. 25-37). Os preconceitos ideológicos conjugam as correntes subterrâneas da cultura ocidental (pangermanismo, arianismo, racismo, anti- 
semitismo) e as mais avançadas conquistas das ciências biológicas e histórico-sociais. A raça ou a classe é esse núcleo preconceituoso da ideologia capaz de explicar tudo e determinar a conduta da população. A ideologia, resultando no conjunto de categorias pseudo-científicas e pseudo-filosóficas, quer ter o domínio das forças ocultas e implacáveis à custa da recusa da realidade. Ela expõe a feição naturalista de qualquer governo totalitário e elimina o sentido originário do poder em Arendt: propiciar o surgimento do homem como um ser capaz de iniciar novos modos de vida, fundar novas instituições e relações.

Em suma, o totalitarismo em Arendt é cheio de especificações e determinações e não um sintagma vazio. Preenchem essa idéia e experiência, em Arendt, as massas, a propaganda, a ideologia, a solidão, o terror e, principalmente, os campos de concentração. Elencar essas características é mais do que simplesmente descrever, é fazer uma espécie de compreensão do presente. É mostrar que as nossas atuais sociedades estão extremamente marcadas por características proto-totalitárias. As novas determinações da política nascidas com o totalitarismo alteraram profundamente o poder. Os termos usados por Arendt podem não ser os mesmos empregados hoje. Contudo, a impressão retida é que suas idéias captaram o nascimento das mudanças que estão em pleno vigor nos dias atuais e anteciparam o que hoje é chamado e atribuído ao biopoder.

\section{Referências bibliográficas}

AGAMBEN, Giorgio. 2002. Homo Sacer. Tradução de Henrique

Burigo. Belo Horizonte: UFMG.

ARENDT, Hannah. 1979. The Origins of Totalitarianism. Nova York: $\mathrm{HB} \& \mathrm{C}$,

1983a. Men in Dark Times. Nova York: HBJ.

1983b. A Condição Humana. Tradução de Roberto

Raposo. Rio de Janeiro: Forense,.

1987a. La tradition cachée. Le juif comme paria. Paris:

Christian Bourgois. 
1987b. Homens em Tempos Sombrios. Tradução de Denise Bottmann. São Paulo: Companhia das Letras.

1988. Entre o Passado e Futuro. Tradução de Mauro

Barbosa de Almeida. São Paulo: Perspectiva.

1990. Origens do Totalitarismo. Tradução de Roberto

Raposo. São Paulo: Companhia das Letras,.

1991. Auschwitz et Jérusalem. Paris: Deux temps-Tierce,

1993. Between Past and Future. Nova York: Penguin

Books.

1994. Essays in Understanding. 1930-1954. New York:

$\mathrm{HB} \& \mathrm{C}$.

1998. O que é a Política. Tradução de Reinaldo

Guarany. Rio de Janeiro: Bertrand Brasil,.

BENHABIB, Seyla. 1990. Hannah Arendt and The Redemptive Power of Narrative. In: Social Research. New York. No 57 p. 166-196.

BERNSTEIN, Richard J. 1996. Hannah Arendt and Jewish Question.

Cambridge: MIT Press.

CALVET, Theresa. 1985. A categoria trabalho (labor) em Hannah Arendt. In: Ensaio. São Paulo. No 14. p. 131-168.

2006. Ação, Linguagem e Poder. In: CORREIA,

Adriano. (Org.) Hannah Arendt e a Condição Humana. Salvador:

Quarteto.

CHALIER, Catherine. 1989. Radicalité et banalité du Mal. In:

ABENSOUR, Miguel. Ontologie et politique. Paris:Tierce.

CHASIN, José. 1977. Sobre o Conceito de Totalitarismo. In: TEMA.

São Paulo: Grijalbo.Vol. 1. p.15-56.

CHAUMONT, J.-M. 1992. La singularité de l'univers

concentrationaire selon Hannah Arendt. In: ROVIELLO, A.-M;

WEIYEMBER GH, M. Hannah Arendt et la modernite. Paris:Vrin. 
COCKS, J. 2002. Passion and Paradox: Intellectuals Confront The National Question. Princeton: Princeton University Press.

LAFER, Celso. 1993. A mentira: um capítulo das relações entre a ética e a política. In: NOVAES, Adauto. (Org.) Ética. São Paulo: Companhia das Letras.

1991. A Reconstrução dos direitos humanos. São Paulo:

Companhia das Letras.

LANG, Berel. 1994. Hannah Arendt and the Politics of Evil. In: HINCHMAN, Lewis P.; HINCHMAN, Sandra K. Hannah Arendt critical essays. New York: State University of New York Press.

LUKÁCS, Georg. 1959. El Asalto a la Razón, Fondo de Cultura Econômica, México.

MACEDO, André Duarte. 2000. O Pensamento à Sombra da ruptura. Rio de Janeiro: Paz e Terra.

SOUKI, Nádia. 1998. Hannah Arendt e a Banalidade do Mal. Belo Horizonte: Ed. UFMG.

STANLEY, John L. 1994. Is totalitarianism a new phenomenon? Reflections on Hannah Arendt's Origins of totalitarianism. In: HINCHMAN, Lewis P.; HINCHMAN, Sandra K. Hannah Arendt critical essays. New York: State University of New York Press.

VOEGELIN, Eric. 1953. A review of The Origins of Totalitarianism, Review of Politics 15, p. 68-76. 